\title{
Competências Gerenciais Requeridas em Empresas FAMILIARES: UM OLHAR FEMININO
}

\section{Skills required in Family Business Management: a feminine look}

\section{Lydia Maria Pinto Brito}

Professora do Programa de Pós-Graduação em Administração, Universidade Potiguar - Fortaleza - CE, Brasil.

E-mail: lydiampbrito@yahoo.com.br.

Nilda Maria de Clodoaldo Guerra Pinto Leone

Professora do Programa de Pós-Graduação em Administração, Universidade Potiguar - Fortaleza - CE, Brasil.

E-mail: leone@openlink.com.br.

\section{Resumo}

O estudo teve como objetivo identificar o perfil de competência das gestoras líderes de empresas familiares. O referencial fundamentou-se em estudos sobre mulheres no comando de empresas familiares e gestão da competência. A pesquisa é caracterizada como exploratória, foi estudada de forma quantitativa, elaborada por meio de uma pesquisa de campo. A amostra foi por acessibilidade e endereçada, especificamente, às empresas familiares sediadas em Natal-RN. O instrumento de coleta de dados foi um questionário. Os dados foram tratados pela estatística descritiva. Os resultados apontam para um Perfil de Competência que indica a percepção da importância da capacitação profissional e gerencial; e de valorização do desenvolvimento pessoal e da ética. Na dimensão do conhecimento confirmase a disposição das pesquisadas pela busca de conhecimento técnico específico do setor de atuação. $\mathrm{Na}$ dimensão habilidade identifica-se a necessidade de melhorar a capacidade de criticar e sintetizar dados e informações sobre processos e pessoas para tomada de decisões. A atitude das gestoras em relação à ética apontou ênfase no sentido do respeito pelo outro, honestidade e justiça nas decisões e coerência entre discurso e prática. Conclui-se esperando que os resultados permitam um melhor gerenciamento de processos de capacitação e desenvolvimento da carreira das gestoras.

Palavras-chave: Gênero Feminino. Competência. Empresa Familiar.

\section{Abstract}

The objective of the study is to identify the profile of competency perceived by the managers of familiar companies. The referential is based on studies on women in the command of familiar companies and competency management. The research was exploratory and quantitative with an accessibility sample of commercial familiar companies in Natal-RN. The instrument of data collection was a questionnaire. The results indicate a categorization of the managers, for the majority $(43.40 \%)$ of proprietors, as the following socioeconomic profile: $2^{\text {nd }}$ degree, age between 36 and 49 years, married with 2 or 3 children. In the knowledge dimension, the results confirmed the disposal for the knowledge search. In ability dimension, we identified the necessity to improve the capacity to criticize and to synthesize data and information about processes and people in the way to the decision making. In the attitude dimension, the managers' perception related to the ethics pointed out great emphasis in the direction of the respect for the other, honesty and justice in the decisions.

Key words: Feminine Gender. Competency. Familiar Company. 


\section{INTRODUÇÃo}

A presença feminina no mercado de trabalho é um fenômeno relativamente recente. A entrada de mulheres nesse mercado, inclusive em áreas antes restritas aos homens, levou as autoras do estudo a formular o seguinte problema de pesquisa: qual o perfil de competência gerencial ideal percebido pelas mulheres proprietárias, dirigentes, empresárias e/ou herdeiras de empresas familiares para o exercício da gestão? O estudo pretende lançar luz sobre a participação da mulher nos processos produtivos e administrativos da empresa familiar, pois a realidade apresenta, cada vez mais, mulheres desempenhando papel-chave na engrenagem familiar.

Assim, este artigo tem por objetivo identificar o perfil de competência profissional percebido pelas mulheres proprietárias, dirigentes, empresárias e/ou herdeiras de empresas familiares em relação a atributos cognitivos e comportamentais requeridos para o exercício da gestão. Objetiva, também, caracterizar essas gestoras de acordo com o desempenho de seus papéis, traçando, ainda, seu perfil socioeconômico.

Sua relevância decorre do fato de que hoje os estudos sobre empresas familiares começam a se concentrar em um dado importante: o aumento das mulheres no comando. Pesquisas importantes são, também, aquelas dedicadas às mulheres empreendedoras, líderes e criadoras de empresas. Aparentemente, o negócio da família teria particulares vantagens para as mulheres, pois, é a empresa familiar a que mais recebe mulheres no comando. $\mathrm{O}$ crescimento da atividade feminina no mercado de trabalho, assim como as transformações no perfil da força de trabalho das futuras primeiras gerações de empresas familiares geridas por mulheres acarretarão, além de alterações no processo sucessório, uma mudança de paradigma que irá modificar, substancialmente, os esquemas de sucessão no futuro. Entretanto, pouco se sabe sobre as competências e o modo de gerir feminino.

O estudo tem como principal referência de análise o entendimento de que a competência é uma combinação de conhecimento, de saber-fazer, de experiências e comportamentos que se exerce em um contexto preciso. É a faculdade de mobilizar redes de atores em torno das mesmas situações, assumindo corresponsabilidades e compartilhando as implicações de suas ações.

Dessa forma, as competências individuais estão representadas de forma esquematizada por atributos cognitivos -conhecimentos que constituem o corpo do saber conceitual dos indivíduos; e comportamentais as habilidades e as atitudes. Assim, habilidade seria o saber fazer, a capacidade de fazer conexões entre situações e dados para aplicar os conhecimentos pela formação, experiências pessoais e vivência profissional; $e$ as atitudes que estão relacionadas aos valores que orientam o comportamento humano e ao querer ser/ fazer, concretizado em ações para atingir a eficiência e a eficácia organizacional.

A pesquisa é caracterizada como exploratória, foi estudada de forma quantitativa, elaborada por meio de uma pesquisa de campo.

Espera-se que os resultados da presente estudo possam indicar ações de desenvolvimento mais orientadas, permitindo assim um melhor gerenciamento de processos de capacitação e desenvolvimento da carreira das mulheres gestoras das empresas familiares.

Este trabalho, além da presente introdução, está estruturado da seguinte forma: (1) fundamentação teórica: por meio de uma pesquisa bibliográfica buscou-se o embasamento teórico e conceitual fundamentando-se o referencial em estudos sobre as mulheres no comando de empresas familiares e perfis de competências (2) metodologia, contendo os procedimentos metodológicos que deram suporte a realização do estudo; (3) análise e interpretação dos resultados; e, por fim, as considerações finais.

\section{FundamentaÇão Teórica}

A fundamentação teórica está apoiada em dois blocos a seguir apresentados: A Empresa Familiar no Feminino e Competências Profissionais.

\subsection{A Empresa Familiar no Feminino}

A empresa familiar é a que mais recebe mulheres no comando, superando a empresa profissional (LEONE; PEREIRA, 2010). Essa afirmação vem ao encontro do pensamento geral que se tem a respeito do tema. Entretanto, Blodel (2005a, p. 25) considera que 
[...] as mulheres ainda são pouco numerosas no papel de direção, mas os números aumentam e as empresas familiares lhes oferecem, provavelmente, mais possibilidades que as outras empresas. As mulheres podem aportar talentos complementares àqueles dos homens, em particular, no que diz respeito a um estilo mais participativo. A diversidade dos gêneros nas equipes dirigentes, frequentemente, pode melhorar a performance da empresa.

Observa Garcia (2001, p. 54) que "[...] alguns autores, estudiosos e psicólogos têm apontado outros aspectos que influenciam a ascensão das filhas mulheres nas empresas familiares [...]" e conclui

[...] a relação pai-filha tende a ser menos turbulenta do que a existente entre pai-filho. A explicação se dá pelo fato de os pais não ver qualquer tipo de ameaça naquilo que as filhas lhes dizem. Além disso, estaria o fato de que as filhas são criadas para dar apoio, mais afinadas às necessidades emocionais e mais preocupadas em dar prioridade à harmonia da família. (GARCIA, 2001, p. 54)

Ao tratar da redefinição dos papéis da mulher na empresa e na família, Blondel (2005a, p. 33) considera que "[...] as mulheres líderes se questionam sobre seus respectivos papéis na família. Vêm mudanças de papéis no casamento, e também, com os outros membros da família: pais, mães, irmãos". Essas mudanças podem, ainda de acordo com a autora, desestabilizar outros membros da família, por isso, diz ser conveniente estar atenta à redefinição dos papéis na empresa e na família. Conclui dizendo que a empresa familiar oferece ocasióes extraordinárias de desempenho de papéis interessantes, que permitem um comprometimento dos atores familiares: membro do Conselho de Administração, membro do Conselho Familiar, comprometimento em uma fundação filantrópica, gestão do patrimônio da holding, dentre outros.

As observações de Silva e Aráoz (2007, p. 1) demonstram que

[...] a mulher começou a mostrar que tem capacidade, através de sua competência, criatividade e maneira de encarar as dificuldades e desafios. Seu crescimento no mercado de trabalho se deve a sua intuição, habilidade com pessoas, busca incessante pelo desenvolvimento das competências e a melhor escolaridade. Outro aspecto que elege a liderança feminina é a sua competência de reconhecer o seu papel transformador na sociedade. Preparam-se para enfrentar o cenário econômico, realizam planejamento, estudam o mercado e promove a inovação como estratégia de competitividade. As "arquitetas do futuro sabem que o futuro é gerenciável e que deve começar no presente. A preocupação com o futuro sinaliza a compreensão e posse de seu papel ativo na elaboração da realidade que virá. De fato, há uma relação direta entre preparação e preocupação com o futuro: as mulheres mais preocupadas com o futuro são justamente as que se preparam.

Esses fatores explicam não apenas o crescimento da atividade feminina, mas também as transformações no perfil da força de trabalho e são necessários para mostrar que apesar da evolução social em que vivemos ainda existem preconceitos. Por essa razão é fundamental a ampla divulgação de histórias vencedoras, demonstrar suas conquistas e evidenciar sua participação no mercado de trabalho.

Os principais papéis desempenhados pelas mulheres nas empresas familiares, no dizer de Ussman (2004) são: mulheres na família; mulheres independentes; mulheres proprietárias; mulheres dirigentes e mulheres empresárias/herdeiras. Para efeito do estudo os três últimos papéis são aqueles que serão observados no presente artigo. Para tanto se dará as suas definições, ainda de acordo com Ussman (2004, p.125).

- Mulheres proprietárias - este grupo de mulheres tem propriedade na capital da empresa $e$ trabalha exercendo uma atividade regular com horário fixo (embora flexível), mas continuam atuando um pouco como matronas da família. As suas opiniões são, sobretudo de âmbito familiar, isto é, sobre o sistema família.

- Mulheres dirigentes - desempenham funções de direção em altos cargos dentro da empresa embora a última decisão seja do empresário, seu marido. Contudo, as suas tarefas são de importância para o dia a dia da empresa, são capazes de substituir os seus maridos na sua ausência, recebem clientes, tomam decisões, apoiam os maridos e as suas opiniões são ouvidas e procuradas. Combinam a sua participação no sistema família com o sistema empresa. 
- Mulheres empresárias/herdeiras - são aquelas que criaram elas mesmas a empresa $e$ por isso assumem o papel de empresárias. A sua atividade está totalmente devotada à empresa e muito raramente o marido está na empresa. Também pode ser o caso de filhas que sucederam a seus pais na direção da empresa, mas cujos maridos aí chegaram a trabalhar, tendo uma atividade profissional independente.

\subsection{Competências Profissionais}

O estudo da competência pode ser considerado um tema emergente na forma de modelo de gestão que valoriza o reconhecimento de dimensões ou indicadores essenciais requeridas pelas situações de trabalho, sobretudo, decorrente das mudanças expressivas no cenário profissional dos últimos 20 anos. Acerca dessas dimensões ou indicadores, desde anos atrás, já existia certo acordo consensual entre pesquisadores nacionais e internacionais - Boyatzis (1982); McLagan (1997); Durand (1998); Fleury e Fleury (2001); Brandão e Guimarães (2002); Ruas (2003) - quanto à importância dos conhecimentos, habilidades e atitudes.

O termo competência possui diferentes níveis de entendimento e aplicação nas organizações, dentre elas, competências essenciais, competências organizacionais e competências individuais.

Para Hamel e Prahalad (1995), a reflexão sobre competências tem como foco a competência essencial da organização, entendida pelos autores como o conjunto de habilidades e experiências, tecnologia, sistemas e ativos estratégicos (tangíveis e intangíveis), processos operacionais e de gestão, valores, normas e comportamentos que devem resultar em um cliente satisfeito ou em um benefício de custo fundamental proporcionando um diferencial competitivo para a organização. Para os autores, as competências essenciais devem responder a três critérios: (1) oferecer reais benefícios aos consumidores (entregar valor); (2) serem difíceis de imitar e; (3) dar acesso a diferentes mercados, resultando em excelência em qualquer área da organização, sendo resultado do aprendizado coletivo.

Nos estudos realizados por Zarifian (1999; 2003) sobre competências observa-se uma estreita relação entre as competências organizacionais e individuais. Zarifian (1999) distingue as competências em uma organização em (1) competências sobre processos - os conhecimentos do processo de trabalho; (2) competências técnicas - conhecimentos específicos sobre o trabalho que deve ser realizado; (3) competencias sobre a organização - saber organizar os fluxos de trabalho; (4) competências sociais - saber ser, incluindo atitudes que sustentam os comportamentos das pessoas e competências de serviço - aliar à competência técnica a pergunta: qual o impacto que este produto ou serviço terá sobre o consumidor final?

Para Zarifian (2001, p. 66)

A competência profissional é uma combinação de conhecimento, de saber-fazer, de experiências e comportamentos que se exerce em um contexto preciso. Ela é constatada quando de sua utilização em situação profissional, a partir da qual é passível de validação. Compete então à empresa identificá-la, avaliá-la, validá-la e fazê-la evoluir.

"Implica em tomar iniciativa e assumir responsabilidade diante de situações profissionais com as quais o indivíduo se depara" (ZARIFIAN, 2001, p. 68). Seria o entendimento prático de situações e que se apoia em conhecimentos adquiridos e os transforma na medida em que aumenta a diversidade das situações. (ZARIFIAN, 2001, p. 72)

\section{Dessa forma,}

[...] competência é a faculdade de mobilizar redes de atores em torno das mesmas situações, é a faculdade de fazer com que esses atores compartilhem as implicações de suas ações, é fazê-los assumir áreas de co-responsabilidade. (ZARIFIAN, 2001, p. 74)

A perspectiva da competência individual possui pelos menos duas abordagens: a da escola norte-americana e a da escola europeia.

A corrente americana se ancora na abordagem comportamentalista, mais especificamente em atributos individuais que justificam o desempenho superior, a formação de times de trabalho ou equipes de alto desempenho. Os estudos de McClelland (1973) sobre o comportamento como uma função da interação entre a pessoa e o ambiente, que buscou identificar quais as características necessárias aos gerentes para alcançar uma alta performance, em grande parte, inspiraram o principal expoente americano. Na construção dessa 
corrente, Boyatzis (1982) entende que a competencia profissional é característica subjacente de uma pessoa, sendo justificada por um motivo, traço, habilidade, aspecto da autoimagem ou papel social, ou um corpo de conhecimento que ela utiliza.

A corrente europeia (de origem francesa, suíça e britânica) tem suporte na abordagem construtivista, sobretudo, na vinculação entre trabalho e educação, cuja resultante pode se concebida por meio de processos sistemáticos de aprendizagem. Conforme essa vertente, conhecimentos, habilidades e atitudes são entendidas como as dimensões que embasam as competências como capacidade pessoal, associando aspectos cognitivos, técnicos, sociais e afetivos vinculados ao trabalho.

Para Durand (1998), a competência é consequência da sinergia resultante dos conhecimentos habilidades e atitudes interdependentes e, sobretudo, necessárias ao alcance de um objetivo específico. E, ao definir competência como a capacidade de se reagir a novas situações tomando-se por base os conhecimentos adquiridos em práticas passadas, Zarifian (2001) acrescentou que a competência é o resultado de um posicionamento pessoal do indivíduo e responsabilidade, expostos dentro de uma situação de trabalho.

Nessa discussão, Perrenoud (2001) enriquece a reflexão fazendo emergir a questão da ética observando que o

[...] reconhecimento de uma competência não passa apenas pela identificação de situações a serem controladas, de problemas a serem resolvidos, de decisões a serem tomadas, mas também pela explicitação dos saberes, das capacidades, dos esquemas de pensamento e das orientações éticas necessárias. (PERRENOUD, 2001, p. 19)

Concordando com Zarifian, Le Boterf (2003, p. 133) entende que "[...] uma das características do profissional é saber mobilizar e combinar, de modo pertinente, um conjunto de "recursos" para administrar uma situação profissional complexa". E acrescenta a questão do contexto maior que influencia e limita o agir, afirmando que para elaborar competências pertinentes a partir dos recursos disponíveis, o profissional não pode somente saber e querer agir, ele deve poder agir (LE BOTERF, 2003, p. 133).

A trajetória histórica e conceitual do estudo da competência vem sugerindo certo acordo consensual para suas denominações ligadas à capacidade, onde se destacam os conhecimentos, habilidade, atitudes ou atributos, dentro de uma visão estratégica, sobretudo, nos níveis individual e organizacional.

No novo milênio, as investigações têm alertado para a aproximação do debate entre competência e capacitação profissional, precisamente, ao evidenciar a necessidade de qualificação no que se trata de estar competente para ou ser competente em determinado domínio (SILVA; HIPÓLITO, 2000; SANCHEZ, 2001; ZARIFIAN, 2001, 2003; RABAGLIO, 2001, 2004; PAIVA; MELO, 2008). Nos estudos sistemáticos se ressalta o nível de complexidade e abrangência da competência em relação à qualificação. Diferentemente do contexto da qualificação a competência não está alinhada ao desempenho em determinado posto de trabalho.

Na avaliação do Perfil de Competência Profissional percebido pelas mulheres proprietárias, dirigentes, empresárias e/ou herdeiras de empresas familiares três elementos devem ser observados: conhecimentos, habilidades e atitudes. O conjunto de conhecimentos, habilidades e atitudes, formam segundo diversos autores, as competências individuais, que viabilizam a competência essencial das organizações.

A investigação da competência profissional no gênero feminino pode ir de encontro às necessidades ditadas pelo mercado de trabalho, no sentido de existir uma combinação de elementos que reproduza o quesito capacidade, que cada vez mais vem se expandindo em termos de oportunidades de trabalho.

\section{Metodologia}

O estudo foi desenvolvido tendo como tema central a gestão da competência no feminino. Teve como objeto as mulheres proprietárias, dirigentes, empresárias e/ou herdeiras de empresas familiares. Define-se o objeto da pesquisa, de acordo com Ussmam (2004, p. 125), nos seguintes termos: mulheres proprietárias este grupo de mulheres tem propriedade no capital da empresa e trabalha exercendo uma atividade regular com horário fixo (embora flexível), mas continuam atuando um pouco como matronas da família. As suas opiniões são, sobretudo de âmbito familiar, isto é, sobre o sistema família; mulheres dirigentes - elas desempenham funções de direção em altos cargos 
dentro da empresa embora a última decisão seja do empresário, seu marido. Contudo, as suas tarefas são de importância para o dia a dia da empresa, são capazes de substituir os seus maridos na sua ausência, recebem clientes, tomam decisões, apoiam os maridos e as suas opiniões são ouvidas e procuradas. Combinam a sua participação no sistema família com o sistema empresa; mulheres empresárias/herdeiras - são aquelas que criaram elas mesmas a empresa e por isso assumem o papel de empresárias. A sua atividade está totalmente direcionada à empresa, e muito raramente o marido está na empresa. Também pode ser o caso de filhas que sucederam a seus pais na direção da empresa, mas cujos maridos chegaram a trabalhar, tendo uma atividade profissional independente.

Por meio de uma pesquisa bibliográfica buscou-se o embasamento teórico e conceitual fundamentando-se o referencial em estudos sobre:

a) mulheres proprietárias, dirigentes ou empresárias desenvolvidos no Brasil e no exterior Garcia (2001); Ussman (2004); Blodel (2005); Silva e Aráo (2007); Leone e Pereira (2010); e

b) competências individuais e organizacionais Boyatzis (1982); Le Boterf 1995, (1999, 2003); Zarifian (2001); McClelland (1973); McLagan (1997); Durand (1998); Silva e Hipólito (2000); Sanchez (2001); Rabaglio (2001, 2004); Brandão e Guimarães (2002); Ruas (2003); Paiva e Melo (2008); Spencer e Spencer (1993); Krogh e Roos (1995); Kamoche (1996); Dutra (2001); Hamel e Prahalad (1995); Vasconcelos e Cyrino (2000); Fleury e Fleury (2000); Herzog (2001); King et al. (2002); Fernandes (2004); Leite e Porsee (2005); Ruas (2005a,b).

A pesquisa é caracterizada como exploratória, foi estudada de forma quantitativa, elaborada por meio de uma pesquisa de campo. Na seleção das empresas pesquisadas foi observado o conceito de empresa familiar trabalhado por Leone (2005) que a caracteriza pela observação dos seguintes fatos: iniciada por um membro da família; membros da família participando da propriedade e/ou direção; valores institucionais identificando-se com um sobrenome de família ou com a figura do fundador e sucessão ligada ao fator hereditário.

A amostra foi por acessibilidade e estava direcionada, especificamente, àquelas empresas que atendiam à definição de empresa familiar e que tinham em seu comando líderes do gênero feminino. O universo da pesquisa foi caracterizado por empresas familiares comerciais e ou industriais sediadas em Natal, RN. Como instrumento de coleta de dados foi utilizado um questionário composto de duas partes: a primeira parte contendo questões referentes às variáveis de identificação das mulheres líderes definidas por meio de uma série de variáveis socioeconômicas, assim apresentadas: gênero, estado civil, número de filhos, idade, nível de escolaridade. Essas variáveis tinham como objetivo categorizar as entrevistadas. A segunda parte do questionário dizia respeito à identificação do perfil de competência das gestoras mulheres proprietárias, dirigentes, empresariais e ou herdeiras das empresas familiares. O instrumento (BRAGA; BRITO, 2009) apresenta dois indicadores: (1) o indicador cognitivo que por meio dos conhecimentos refere-se ao saber teórico, conceitual, fundamental para orientar uma boa prática de gestão e (2) o indicador comportamental que comporta as habilidades (referindo-se ao saber fazer, isto é, a capacidade de aplicar os conhecimentos teóricos) e a atitude (referindo-se a querer ser/fazer a partir da decisão e motivação pessoal). A dimensão Conhecimento foi analisada por meio de dez variáveis; analisou-se a dimensão Habilidade por meio de 12 variáveis, enquanto por meio de sete variáveis as atitudes foram analisadas. As variáveis foram apresentadas em escala de 1 a 5 diante das quais as pesquisadas teriam de assinalar sua percepção a respeito do assunto indagado. O instrumento de pesquisa foi adaptado de Braga e Brito (2009). Os dados foram tratados por meio da estatística descritiva.

O esquema geral da pesquisa é apresentado a seguir. 


\begin{tabular}{|c|c|c|}
\hline OBJEtivos & VARIÁVEIS & INDICADORES \\
\hline \multirow{3}{*}{$\begin{array}{l}\text { Identificar o Perfil de } \\
\text { Competência percebido } \\
\text { pelas mulheres proprietárias, } \\
\text { dirigentes, empresárias e/ou } \\
\text { herdeiras de empresas familiares. }\end{array}$} & $\begin{array}{l}\text { Nível de importância } \\
\text { do Indicador } \\
\text { Cognitivo } \\
\text { Conhecimentos }\end{array}$ & $\begin{array}{l}\text { Área/Setor de atuação da empresa familiar (Política, } \\
\text { sistema, mercado); Administração/Finanças; Planejamento } \\
\text { Estratégico e Operacional; Gestão de pessoas; Técnico } \\
\text { Específico; Informática; Processo de Tomada de Decisão; } \\
\text { Gestão de Qualidade; Psicologia Organizacional; Produto/ } \\
\text { Mercado de atuação da Empresa/Instituição. }\end{array}$ \\
\hline & $\begin{array}{l}\text { Nível de importância } \\
\text { do Indicador } \\
\text { Comportamental } \\
\text { Habilidades }\end{array}$ & $\begin{array}{l}\text { Planejamento; Organização; Liderança; Decisão; } \\
\text { Comunicação/ saber ouvir; Análise e Síntese; Trabalho } \\
\text { em Equipe; Criatividade/Inovação; Execução; Inspiração } \\
\text { e Motivação da Equipe; Administração de Conflito e } \\
\text { Negociação; Relações Interpessoais. }\end{array}$ \\
\hline & $\begin{array}{l}\text { Nível de importância } \\
\text { do Indicador } \\
\text { Comportamental } \\
\text { Atitudes }\end{array}$ & $\begin{array}{l}\text { Ético; Autoconfiante; Determinado; Flexível; Responsável; } \\
\text { Servidor/ Cuidadoso; Comprometido. }\end{array}$ \\
\hline $\begin{array}{l}\text { Caracterizar as gestoras de } \\
\text { empresas familiares de acordo } \\
\text { com os papéis desempenhados } \\
\text { e perfil socioeconômico. }\end{array}$ & Perfil socioeconômico & $\begin{array}{l}\text { Nível de escolaridade; Área da formação acadêmica; } \\
\text { Formação em nível de pós-graduação; Idade; Estado civil; } \\
\text { número de filhos; }\end{array}$ \\
\hline
\end{tabular}

Quadro 1: Esquema geral de pesquisa

Fonte: Elaborado pelas autoras deste artigo

\section{Apresentação e Análise dos Resultados}

Nesta seção estão apresentados os dados obtidos na pesquisa. Em primeiro lugar a categorização das gestoras de empresas familiares de acordo com os papéis desempenhados, seguida do perfil de competência obtido e finalmente a apresentação de alguns dados gerais do estudo.

\subsection{Categorização das Gestoras de Empresas Familiares de Acordo com os Papéis Desempenhados}

O grupo de entrevistadas deste estudo é composto de 13 gestoras mulheres proprietárias, nove dirigentes, seis empresárias e duas herdeiras das empresas familiares localizadas em Natal, RN. A amostra revela que a maioria das mulheres gestoras são proprietárias de suas empresas tendo a propriedade do capital e exercendo uma atividade regular com horário fixo.

Essa evidência vai de encontro às afirmações de Blodel (2005b) ao prospectar que grande parte dos primeiros fundadores de empresas familiares serão mulheres. Fato que poderá comprovar a mudança de paradigma nos esquemas de sucessão no futuro.

Com escolaridade de $2^{\circ}$ grau, idade entre 36 a 49 anos, casada, com dois a três filhos caracteriza-se o perfil da mulher proprietária. Quanto à mulher dirigente seu perfil é assim caracterizado: $2^{\circ}$ grau de escolaridade, a idade variando entre 25 a 35 anos, casada com um filho. A mulher empresária tem escolaridade de $2^{\circ}$ grau, idade entre 36 a 49 anos, solteira com dois filhos. As herdeiras posicionam-se com escolaridade entre $1^{\circ}$ e $2^{\circ}$ graus, com idade entre 25 a 35 anos, casadas, com um filho.

A escolaridade é uma variável que desperta atenção. A maioria das gestoras das empresas familiares tem o $2^{\circ}$ grau como nível de escolaridade. A esse respeito assim se posicionam Silva e Aráoz (2007, p. 1) "[...] a expansão de escolaridade e o ingresso nas universidades viabilizaram o acesso das mulheres a novas oportunidades".

O perfil socioeconômico das gestoras de empresas familiares por papel desempenhado apresenta-se da seguinte forma. 
Tabela 1: Categorização das gestoras de acordo com os papéis desempenhados

\begin{tabular}{|l|l|l|l|}
\hline \multicolumn{1}{|c|}{ PAPEL } & \multicolumn{1}{c|}{ DefiNição } & F & \% \\
\hline Proprietária & $\begin{array}{l}\text { Este grupo de mulheres tem propriedade no capital da empresa e trabalha exercendo } \\
\text { uma atividade regular com horário fixo (embora flexível), mas continuam atuando um } \\
\text { pouco como matronas da família. As suas opiniôes são, sobretudo, de âmbito familiar, } \\
\text { isto é, sobre o sistema família. }\end{array}$ & 13 & 43,40 \\
\hline Dirigente & $\begin{array}{l}\text { Essas desempenham funções de direção em altos cargos dentro da empresa embora } \\
\text { a última decisão seja do empresário, seu marido. Contudo, as suas tarefas são de } \\
\text { importância para o dia a dia da empresa, são capazes de substituir os seus maridos } \\
\text { na sua ausência, recebem clientes, tomam decisões, apoiam os maridos e as suas } \\
\text { opiniões são ouvidas e procuradas. Combinam a sua participação no sistema família } \\
\text { com o sistema empresa. }\end{array}$ & 09 & 30,00 \\
\hline Empresária & $\begin{array}{l}\text { São aquelas que criaram elas mesmas a empresa e por isso assumem o papel de } \\
\text { empresárias. A sua atividade está totalmente devotada à empresa e muito raramente } \\
\text { o marido está na empresa. }\end{array}$ & 06 & 20,00 \\
\hline Herdeira & $\begin{array}{l}\text { Caso de filhas que sucederam a seus pais na direção da empresa, mas cujos maridos } \\
\text { aí chegaram a trabalhar, tendo uma atividade profissional independente. }\end{array}$ & 02 & 6,60 \\
\hline Total & & 30 & 100,00 \\
\hline
\end{tabular}

Fonte: Pesquisa de Campo (2010)

Tabela 2: Perfil socioeconômico das gestoras por papel desempenhado

\begin{tabular}{|c|c|c|c|c|}
\hline \multirow{2}{*}{ 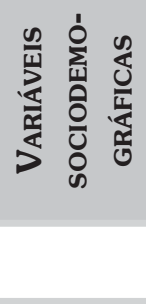 } & \multicolumn{4}{|c|}{ PAPEL DESEMPENHADO } \\
\hline & $\begin{array}{c}\text { Proprie- } \\
\text { tária }\end{array}$ & $\begin{array}{l}\text { Diri- } \\
\text { gente }\end{array}$ & $\begin{array}{c}\text { Empre- } \\
\text { sária }\end{array}$ & Herdeira \\
\hline $\begin{array}{l}\text { Escolari- } \\
\text {-dade }\end{array}$ & $2^{\circ}$ Grau & $\begin{array}{l}2^{\circ} \\
\text { Grau }\end{array}$ & $2^{\circ} \mathrm{Grau}$ & $\begin{array}{l}1^{\circ} \text { e } 2^{\circ} \\
\text { Grau }\end{array}$ \\
\hline $\begin{array}{l}\text { Faixa } \\
\text { etária }\end{array}$ & $\begin{array}{l}36 \text { a } 49 \\
\text { anos }\end{array}$ & $\begin{array}{l}25 \text { a } \\
35 \\
\text { anos }\end{array}$ & $\begin{array}{l}36 \text { a } 49 \\
\text { anos }\end{array}$ & $\begin{array}{l}25 \text { a } 35 \\
\text { anos }\end{array}$ \\
\hline $\begin{array}{l}\text { Estado } \\
\text { civil }\end{array}$ & casada & casada & solteira & casada \\
\hline $\begin{array}{l}\text { Números } \\
\text { de filhos }\end{array}$ & $\begin{array}{l}\text { dois } \\
\text { a três } \\
\text { filhos }\end{array}$ & $\begin{array}{l}\text { um } \\
\text { filho }\end{array}$ & $\begin{array}{l}\text { dois } \\
\text { filhos }\end{array}$ & um filho \\
\hline Total & 13 & 09 & 06 & 02 \\
\hline
\end{tabular}

Fonte: Dados da Pesquisa de Campo (2010)

O perfil socioeconômico das gestoras de empresas familiares caracteriza-se da seguinte forma: quanto ao papel desempenhado pelas gestoras $43,40 \%$ delas são proprietárias de seus negócios, com idades entre 36 a 49 anos $(43,00 \%)$, casadas $(57,00 \%)$, com um ou dois filhos $(50,00 \%)$ e escolaridade de $2^{\circ}$ grau $(60,00 \%)$.

O perfil socioeconômico das gestoras de empresas familiares pode ser visto a seguir:
Tabela 3: Perfil Socioeconômico das gestoras de empresas familiares

\begin{tabular}{|c|c|c|c|}
\hline \multicolumn{2}{|c|}{ INDICADOR } & 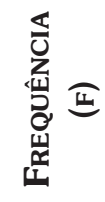 & 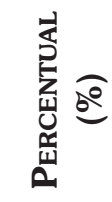 \\
\hline \multirow{4}{*}{$\begin{array}{l}\text { Situação da } \\
\text { gestora da } \\
\text { empresa }\end{array}$} & Proprietária & 13 & 43,40 \\
\hline & Dirigente & 09 & 30,00 \\
\hline & Empresária & 06 & 20,00 \\
\hline & Herdeira & 02 & 6,60 \\
\hline \multirow{3}{*}{ Idade } & Entre 25 e 35 anos & 11 & 37,00 \\
\hline & Entre 36 e 49 anos & 13 & 43,00 \\
\hline & Mais de 49 anos & 6 & 20,00 \\
\hline \multirow{3}{*}{ Escolaridade } & $1^{\circ} \mathrm{Grau}$ & 2 & 6,00 \\
\hline & $2^{\circ} \mathrm{Grau}$ & 18 & 60,00 \\
\hline & $3^{\circ} \mathrm{Grau}$ & 10 & 33,00 \\
\hline \multirow{3}{*}{ Estado Civil } & Solteira & 10 & 33,00 \\
\hline & Casada & 17 & 57,00 \\
\hline & Divorciada & 3 & 10,00 \\
\hline \multirow{3}{*}{$\begin{array}{l}\text { Número } \\
\text { de Filhos }\end{array}$} & Sem filhos & 8 & 27,00 \\
\hline & Um ou dois filhos & 15 & 50,00 \\
\hline & $\begin{array}{l}\text { Três ou quatro } \\
\text { filhos }\end{array}$ & 7 & 23,00 \\
\hline
\end{tabular}

Fonte: Dados da Pesquisa de Campo (2010) 


\subsection{Identificar o Perfil de Competência das Gestoras de Empresas Familiares}

O perfil de competência, segundo a abordagem de Durand (1998) utilizada na presente pesquisa, será apresentado em três dimensões: conhecimentos, habilidades e atitudes.

\subsubsection{Dimensão Conhecimentos - indicador cognitivo}

A dimensão Conhecimento atrelada ao indicador cognitivo se refere ao saber teórico/conceitual, fundamental para orientar uma boa prática $e$ foi pesquisado por meio de dez variáveis, conforme resultados analisados sequencialmente aqui mostrados na Tabela 4.

O conhecimento é constituído pelo corpo do saber, referindo-se ao saber teórico, conceitual e fundamental para orientar a boa prática organizacional.

Na gestão de competência profissional, na dimensão cognitiva do conhecimento, as gestoras mulheres proprietárias, dirigentes e empresárias/herdeiras das empresas familiares de Natal percebem essa dimensão localizando-a, quanto às médias, entre "extrema importância" e "muito importante".

Suas respostas sobre o conhecimento do setor atuação da Empresa (40\%), da Administração e Finanças (37\%), dos conhecimentos técnicos específicos (43\%), da Gestão da Qualidade (37\%), da Psicologia Organizacional $(30 \%)$ foram consideradas de "extrema importância”, enquanto os conhecimentos sobre Planejamento Estratégico e Operacional (47\%), Gestão de Pessoas (30\%), Informática (37\%), Processo de Tomada de Decisão (47\%), Produto/Mercado de atuação (40\%) foram percebidas como de "muita importância".

Pode-se concluir, pela análise dos dados, uma maior relevância às áreas funcionais da empresa destacando-se a administração e finanças, conhecimentos técnicos específicos e gestão da qualidade, em detrimento das áreas consideradas cada vez mais importantes nos modelos de gestão contemporâneos como o planejamento estratégico e operacional, a

Tabela 4: Dados referentes às variáveis da Dimensão Conhecimento - Indicador cognitivo

\begin{tabular}{|c|c|c|c|c|c|c|c|c|c|c|}
\hline \multirow[t]{2}{*}{ VARIÁVEL } & \multicolumn{2}{|c|}{$\begin{array}{c}\text { GRAU } 5 \\
\text { EXTREMA } \\
\text { IMPORTÂNCIA }\end{array}$} & \multicolumn{2}{|c|}{$\begin{array}{l}\text { Grau } 4 \text { MuITo } \\
\text { IMPORTANTE }\end{array}$} & \multicolumn{2}{|c|}{$\begin{array}{c}\text { GRAU } 3 \\
\text { BASTANTE } \\
\text { IMPORTANTE }\end{array}$} & \multicolumn{2}{|c|}{$\begin{array}{c}\text { GRAU } 2 \\
\text { IMPORTANTE }\end{array}$} & \multicolumn{2}{|c|}{$\begin{array}{c}\text { GRAU 1 } \\
\text { MENOR } \\
\text { IMPORTÂNCIA }\end{array}$} \\
\hline & $\mathbf{F}$ & $\%$ & $\mathbf{F}$ & $\%$ & $\mathbf{F}$ & $\%$ & $\mathbf{F}$ & $\%$ & $\mathbf{F}$ & $\%$ \\
\hline 1 Setor de atuação & 12 & $40 \%$ & 07 & $23 \%$ & 06 & $20 \%$ & 05 & $16 \%$ & 00 & $0 \%$ \\
\hline $\begin{array}{l}2 \text { Administração/ } \\
\text { Finanças }\end{array}$ & 11 & $37 \%$ & 09 & $30 \%$ & 04 & $13 \%$ & 06 & $20 \%$ & 00 & $0 \%$ \\
\hline $\begin{array}{l}3 \text { Planejamento } \\
\text { Estratégico e } \\
\text { Operacional }\end{array}$ & 04 & $13 \%$ & 14 & $47 \%$ & 05 & $16 \%$ & 07 & $23 \%$ & 00 & $0 \%$ \\
\hline 4 Gestão de Pessoas & 06 & $20 \%$ & 09 & $30 \%$ & 06 & $20 \%$ & 08 & $27 \%$ & 01 & $3 \%$ \\
\hline $\begin{array}{l}5 \text { Conhecimento } \\
\text { Específico }\end{array}$ & 13 & $43 \%$ & 05 & $16 \%$ & 04 & $13 \%$ & 05 & $16 \%$ & 03 & $10 \%$ \\
\hline 6 Informática & 03 & $10 \%$ & 11 & $37 \%$ & 06 & $20 \%$ & 05 & $16 \%$ & 05 & $16 \%$ \\
\hline 7 Tomada de decisão & 03 & $10 \%$ & 14 & $47 \%$ & 06 & $20 \%$ & 06 & $20 \%$ & 01 & $3 \%$ \\
\hline $\begin{array}{l}8 \text { Gestão da } \\
\text { Qualidade }\end{array}$ & 11 & $37 \%$ & 08 & $27 \%$ & 03 & $10 \%$ & 07 & $23 \%$ & 01 & $3 \%$ \\
\hline $\begin{array}{l}9 \text { Psicologia } \\
\text { Organizacional }\end{array}$ & 09 & $30 \%$ & 13 & $43 \%$ & 01 & $3 \%$ & 04 & $13 \%$ & 03 & $10 \%$ \\
\hline $\begin{array}{l}10 \text { Produto/ Mercado } \\
\text { de atuação }\end{array}$ & 07 & $23 \%$ & 12 & $40 \%$ & 06 & $20 \%$ & 05 & $16 \%$ & 00 & $0 \%$ \\
\hline
\end{tabular}

Fonte: Dados da Pesquisa de Campo (2010) 
gestão das pessoas, a informática e o processo de tomada de decisão.

Tais dados demonstram um estilo de gestão tradicional que pode ter sido adquirido por meio da transferência de conhecimentos dos fundadores, dirigentes e empresários, reforçando as colocações de Sveiby (1998) de que as organizações podem adotar estratégia de transferência de conhecimento por meio da tradição.

De modo geral, confirma-se a disposição das pesquisadas pela busca de conhecimento, destacando a importância do aprendizado na qualidade de filhas nos negócios familiares, conforme constata Inácio (2006). Conclui-se pela relevância de que os conhecimentos sejam adquiridos não apenas pela tradição e de forma tácita de pais para filhas, mas que as gestoras busquem nas universidades e em cursos seu constante aperfeiçoamento.

\subsubsection{Dimensão Habilidade -Indicador Comportamental}

A dimensão Habilidade tratada por intermédio do indicador comportamental se refere ao saber fazer e consiste na capacidade de aplicar os conhecimentos teóricos e foi pesquisado por meio de 12 variáveis, conforme resultados analisados sequencialmente aqui mostrados na Tabela 5.

A habilidade refere-se à capacidade de aplicar os conhecimentos pela formação, experiências pessoais e vivência profissional. É a capacidade de aplicar os conhecimentos teóricos. As gestoras familiares perceberam essa dimensão localizando-a entre de "extrema importância" a "muito importante".

As variáveis que dizem respeito ao Planejamento (43\%), a Comunicação (43\%), a Execução (43\%), a Inspiração e Motivação da Equipe (43\%), a Adminis-

Tabela 5: Dados referentes às variáveis da Dimensão Habilidade - Indicador comportamental

\begin{tabular}{|c|c|c|c|c|c|c|c|c|c|c|}
\hline \multirow[t]{2}{*}{ VARIÁVEL } & \multicolumn{2}{|c|}{$\begin{array}{c}\text { GRAU } 5 \\
\text { EXTREMA } \\
\text { IMPORTÂNCIA }\end{array}$} & \multicolumn{2}{|c|}{$\begin{array}{l}\text { Grau } 4 \text { MuIto } \\
\text { IMPORTANTE }\end{array}$} & \multicolumn{2}{|c|}{$\begin{array}{c}\text { Grau } 3 \\
\text { BASTANTE } \\
\text { IMPORTANTE }\end{array}$} & \multicolumn{2}{|c|}{$\begin{array}{c}\text { GRAU } 2 \\
\text { IMPORTANTE }\end{array}$} & \multicolumn{2}{|c|}{$\begin{array}{c}\text { Grau } 1 \\
\text { MenOR } \\
\text { IMPORTÂNCIA }\end{array}$} \\
\hline & $\mathbf{F}$ & $\%$ & $\mathbf{F}$ & $\%$ & $\mathbf{F}$ & $\%$ & $\mathbf{F}$ & $\%$ & $\mathbf{F}$ & $\%$ \\
\hline 1 Planejamento & 09 & $30 \%$ & 13 & $43 \%$ & 04 & $13 \%$ & 03 & $10 \%$ & 01 & $3 \%$ \\
\hline 2 Organização & 12 & $40 \%$ & 10 & $33 \%$ & 05 & $16 \%$ & 02 & $6 \%$ & 01 & $3 \%$ \\
\hline 3 Liderança & 12 & $40 \%$ & 08 & $27 \%$ & 03 & $10 \%$ & 07 & $23 \%$ & 00 & $\%$ \\
\hline 4 Decisão & 13 & $43 \%$ & 09 & $30 \%$ & 04 & $13 \%$ & 04 & $13 \%$ & 00 & $\%$ \\
\hline 5 Comunicação & 10 & $33 \%$ & 13 & $43 \%$ & 06 & $20 \%$ & 01 & $3 \%$ & 00 & $\%$ \\
\hline 6 Análise e Síntese & 08 & $27 \%$ & 08 & $27 \%$ & 05 & $16 \%$ & 08 & $27 \%$ & 01 & $3 \%$ \\
\hline 7 Trabalho equipe & 14 & $47 \%$ & 11 & $37 \%$ & 01 & $3 \%$ & 04 & $13 \%$ & 00 & $5 \%$ \\
\hline 8 Criatividade & 20 & $66 \%$ & 07 & $23 \%$ & 01 & $3 \%$ & 02 & $6 \%$ & 00 & $\%$ \\
\hline 9 Execução & 09 & $30 \%$ & 13 & $43 \%$ & 05 & $16 \%$ & 03 & $10 \%$ & 00 & $5 \%$ \\
\hline $\begin{array}{l}10 \text { Inspiração/ } \\
\text { motivação }\end{array}$ & 10 & $33 \%$ & 13 & $43 \%$ & 00 & $0 \%$ & 07 & $23 \%$ & 00 & $5 \%$ \\
\hline $\begin{array}{l}11 \text { Conflito/ } \\
\text { negociação }\end{array}$ & 09 & $30 \%$ & 16 & $53 \%$ & 02 & $6 \%$ & 02 & $6 \%$ & 01 & $3 \%$ \\
\hline $\begin{array}{l}12 \text { Relações } \\
\text { Interpessoais }\end{array}$ & 10 & $33 \%$ & 08 & $27 \%$ & 07 & $23 \%$ & 05 & $16 \%$ & 00 & $\%$ \\
\hline
\end{tabular}

Fonte: Dados da Pesquisa de Campo (2010) 
tração de Conflito e a Negociação (53\%) foram percebidas como muito importantes enquanto a capacidade de Organização (40\%), de Liderança (4.0), de Decisão (43\%), trabalho em equipe (47\%), de Criatividade/ Inovação (66\%) e Relações Interpessoais (33\%) foram percebidos de extrema importância. Cabe ressaltar a percepção das gestoras das empresas familiares sobre a administração de conflito e negociação. A variável é vista por $53 \%$ das pesquisadas como "muito importante". A variável Análise e Síntese foi percebida nos três graus 5, 4 e 3, "extrema importância", "muito importante" e "bastante importante". As gestoras ainda necessitam melhorar sua capacidade de criticar e sintetizar dados e informações sobre processos e pessoas para tomada de decisões.

O saber ouvir (Comunicação), o trabalho em equipe e a gestão de conflitos estão diretamente relacionados com a liderança $e$ as relações interpesssoais que inspiram e motivam a equipe. Segundo Gutierrez (1999), para melhorar a qualidade da comunicação, o ser humano tem que desenvolver as habilidades de se expressar e de ouvir. Observa-se que as percepções das gestoras familiares pesquisadas estão em consonância com a escola americana, segundo a qual e ao seu seguidor McClelland (1973), a competência individual é entendida como uma característica individual relacionada com o desempenho superior na execução de algo ou em uma determinada situação.

\subsubsection{Dimensão Atitude - Indicador Comportamental}

A dimensão Atitude abordada por meio do indicador comportamental se refere ao querer ser/fazer a partir da decisão e motivação pessoal e foi pesquisado por meio de sete variáveis, conforme resultados analisados sequencialmente aqui mostrados na Tabela 6 .

A dimensão atitude está relacionada ao querer ser e/ou fazer, pertinente ao comportamento, para se atingir a eficiência e a eficácia organizacionais. É o querer ser ou querer fazer a partir da decisão e motivação pessoal.

As gestoras das empresas familiares de Natal percebem essa dimensão localizando-a entre "extrema importância" e "muito importante".

As variáveis que dizem respeito à determinação (53\%) e a flexibilidade ( $43 \%$ ) foram percebidas como "muito importantes", enquanto as atitudes referentes à ética (66\%), ao autocontrole (53\%), a responsabilidade (57\%), a servidão ( $47 \%$ ) e ao comprometimento (50\%) foram percebidas pelas gestoras das empresas familiares como de "extrema importância".

A atitude das gestoras pesquisadas em relação à ética apontou a grande ênfase no sentido do respeito pelo outro, honestidade e justiça nas decisões e coerência entre discurso e prática, incluindo o querer ser e/ ou fazer. Essa competência, orientada para o trabalho,

Tabela 6: Dados referentes às variáveis da Dimensão Atitude - Indicador comportamental

\begin{tabular}{|c|c|c|c|c|c|c|c|c|c|c|}
\hline \multirow[t]{2}{*}{ VARIÁVEL } & \multicolumn{2}{|c|}{$\begin{array}{c}\text { GRAU } 5 \\
\text { EXTREMA } \\
\text { IMPORTÂNCIA }\end{array}$} & \multicolumn{2}{|c|}{$\begin{array}{l}\text { Grau } 4 \text { Muito } \\
\text { Importante }\end{array}$} & \multicolumn{2}{|c|}{$\begin{array}{c}\text { Grau } 3 \\
\text { Bastante } \\
\text { Importante }\end{array}$} & \multicolumn{2}{|c|}{$\begin{array}{c}\text { GRAU } 2 \\
\text { IMPORTANTE }\end{array}$} & \multicolumn{2}{|c|}{$\begin{array}{c}\text { Grau } 1 \\
\text { MENOR } \\
\text { IMPORTÂNCIA }\end{array}$} \\
\hline & $\mathbf{F}$ & $\%$ & $\mathbf{F}$ & $\%$ & $\mathbf{F}$ & $\%$ & $\mathbf{F}$ & $\%$ & $\mathbf{F}$ & $\%$ \\
\hline 1 Ético & 20 & $66 \%$ & 07 & $23 \%$ & 01 & $3 \%$ & 02 & $6 \%$ & 00 & $\%$ \\
\hline 2 Autoconfiante & 16 & $53 \%$ & 09 & $30 \%$ & 03 & $10 \%$ & 02 & $6 \%$ & 00 & $\%$ \\
\hline 3 Determinado & 06 & $20 \%$ & 16 & $53 \%$ & 05 & $16 \%$ & 03 & $10 \%$ & 00 & $\%$ \\
\hline 4 Flexível & 09 & $30 \%$ & 13 & $43 \%$ & 02 & $6 \%$ & 06 & $20 \%$ & 00 & $\%$ \\
\hline 5 Responsável & 17 & $57 \%$ & 06 & $20 \%$ & 04 & $13 \%$ & 03 & $10 \%$ & 00 & $\%$ \\
\hline 6 Servidor & 14 & $47 \%$ & 12 & $40 \%$ & 2 & $6 \%$ & 2 & $6 \%$ & 00 & $\%$ \\
\hline 7 Comprometido & 15 & $50 \%$ & 11 & $37 \%$ & 02 & $6 \%$ & 02 & $6 \%$ & 00 & $\%$ \\
\hline
\end{tabular}

Fonte: Dados da Pesquisa de Campo (2010) 
proveniente de atividades sistemáticas, é observada pelos valores obtidos nas respostas dadas. Sugere-se, entretanto, maior flexibilidade e determinação por parte das gestoras, pois diante da nova realidade organizacional de rápidas e constantes mudanças, as organizações gerenciadas nos moldes taylorianos estão cada vez mais cedendo espaço a novas formas de gestão.

Finalmente, identifica-se que a categorização das gestoras de empresas familiares de acordo com os papéis desempenhados, assim se apresenta: o grupo de entrevistadas deste estudo é composto de 13 gestoras mulheres proprietárias, nove dirigentes, seis empresárias e dois herdeiras das empresas familiares localizadas em Natal, RN. A amostra revela que a maioria das mulheres gestoras são proprietárias de suas empresas tendo a propriedade do capital e exercendo uma atividade regular com horário fixo. Essa evidência vai de encontro às afirmações de Blodel (2005b) ao prospectar que grande parte dos primeiros fundadores de empresas familiares serão mulheres. Fato que poderá comprovar a mudança de paradigma nos esquemas de sucessão no futuro. Em relação ao perfil socioeconômico da amostra das investigadas demonstra que o papel desempenhado pelas gestoras é de proprietária de seus negócios, com idades entre 36 a 49 anos, casadas, com um ou dois filhos e escolaridade de $2^{\circ}$ grau.

Quanto ao perfil de competência, apoiado nos ensinamentos de Durand (1998), os dados demonstraram resultados superiores a "muito importante" para todas as variáveis analisadas, indicando uma percepção de "muito importante" e de "extrema importância" para os três grupos de elementos.

Em relação à dimensão Conhecimentos - Indicador cognitivo: as variáveis estudadas localizaram-se entre "extrema importância" e "muito importante". Confirma-se a disposição das pesquisadas pela busca de conhecimento.

Em relação à dimensão Habilidade -Indicador comportamental: asvariáveis estudadas localizaram- se entre "extrema importância" e "muito importante". Entretanto no que diz respeito à variável 6 (análise e síntese) o posicionamento dos entrevistados apontou para o grau "importante". As gestoras ainda necessitam melhorar sua capacidade de criticar e sintetizar dados e informações sobre processos e pessoas para tomada de decisões.
Em relação à dimensão Atitude - Indicador comportamental: a atitude das gestoras pesquisadas em relação à ética apontou a grande ênfase no sentido do respeito pelo outro, honestidade e justiça nas decisões e coerência entre discurso e prática, incluindo o querer ser e/ou fazer.

\section{Considerações Finais}

O objetivo traçado de identificar o perfil de competência profissional percebido pelas mulheres proprietárias, dirigentes, empresárias e/ou herdeiras de empresas familiares pode ser assim apresentado: reconhecimento da importância da capacitação profissional e gerencial; e valorização do desenvolvimento pessoal e da ética.

Consideram de extrema importância os conhecimentos sobre o setor de atuação da Empresa, a administração e finanças, os conhecimentos técnicos específicos, a gestão da qualidade e a psicologia organizacional. Consideram, entretanto, muito importantes os conhecimentos relativos ao planejamento estratégico e operacional, a gestão de pessoas, a informática, o processo de tomada de decisão, assim como o produto ou mercado de atuação. Conclui-se que as gestoras privilegiam as áreas funcionais da empresa, em detrimento das áreas consideradas cada vez mais importantes nos modelos de gestão contemporâneos.

Foram percebidas, como de extrema importância, as habilidades referentes à capacidade de organização, de liderança, de decisão, de trabalho em equipe, de criatividade/inovação e relações interpessoais, enquanto as habilidades referentes ao planejamento; a comunicação; a execução; a inspiração e a motivação da equipe; e a administração de conflito e de negociação foram percebidas como muito importantes. As gestoras ainda necessitam melhorar sua capacidade de criticar e sintetizar dados e informações sobre processos e pessoas para tomada de decisões, já que a variável análise e síntese foi percebida com diferentes graus de importância.

Consideram de extrema importância as atitudes referentes à ética, ao autocontrole, à responsabilidade, à servidão e ao comprometimento. Percebem como muito importantes as atitudes que dizem respeito à determinação e a flexibilidade 
Na dimensão do conhecimento confirma-se a disposição das pesquisadas pela busca de conhecimento técnico específico do setor de atuação. Na dimensão habilidade identifica-se a necessidade de melhorar a capacidade de criticar e sintetizar dados e informações sobre processos e pessoas para tomada de decisões. $\mathrm{Na}$ dimensão atitude destacou-sea ética com grande ênfase no sentido do respeito pelo outro, honestidade e justiça nas decisões. Conclui-se que as gestoras percebem como "muito importante" a necessidade do desenvolvimento pessoal e profissional contínuo para o exercício gerencial.

Os resultados parecem recomendar investimento em ações de capacitação e desenvolvimento contemplando todas as dimensões do perfil de competência, tanto nos aspectos cognitivos, como comportamentais. Assim, propiciando condições de superação dos modelos cartesianos de orientação taylorista-fordista, voltados apenas a execução dos trabalhos rotineiros e de resultados imediatos, para capacitações direcionadas ao desenvolvimento das gestoras de empresas familiares em temáticas relativas à construção de uma visão estratégica, holística e de longo prazo.

Consequentemente, o ato de indicar ações de desenvolvimento mais orientadas estrategicamente permitindo assim um melhor gerenciamento de processos de capacitação e desenvolvimento da carreira das gestoras de empresas familiares, implica na sinalização de processos educativos voltados: aos novos modelos de gestão, ao desenvolvimento de competências e a valorização do capital humano da empresa, fatores críticos de sucesso e competitividade

\section{REFERÊNCIAS}

BLONDEL, C. Les femmes et l'entreprise familale: rôles er évolution. Working paperseries. Centre International Wendel pour l'Entreprise Familiale: INSEA, 2005a.

\section{BLONDEL, C. Las mujeres y la empresa familiar:}

funciones y evolución. Barcelona: Pricewaterhouse Coopers/Associació Catalana de l'empresa familiar, 2005b.

BOYATZIS, R. E. The competent manager: a model for effective performance. New York: John Wiley \& Sons, 1982.
BRAGA, J. L.; BRITO, L. M. P. Perfil ideal de competência profissional de gestores da área de saúde. In: Encontro de Gestão de Pessoas e Relações de Trabalho - ENGPR/ ANPAD, II, 2009. Curitiba. Anais... Curitiba: SCAN Editoração \& Produção Gráfica, 2009.

BRANDÃO, H. P.; GUIMARÃES, T. A. Gestão de Competências e Gestão de Desempenho. In: WORD JR., T. (Org). Gestão empresarial: o fator humano. São Paulo: Atlas, 2002.

DURAND, T. Forms of incompetence. In: International conference on competence-based management,

4. Oslo. Proceedings... Oslo: Norwegian School of Management, 1998.

DUTRA, J. Gestão de Pessoas com Base em Competências. In: DUTRA, J. (Org.). Gestão por competências. São Paulo, SP: Gente, 2001.

FERNANDES, B. H. R. Competências e performance organizacional: um estudo empírico. 232fls. Tese (Doutorado) - Faculdade de Economia e Administração. São Paulo: Universidade de São Paulo, 2004.

FLEURY, A. C. C.; FLEURY, M. T. Estratégias empresariais e formação de competências. São Paulo: Atlas, 2000.

FLEURY, A.; FLEURY, M. T. L. Construindo o Conceito de Competência. Revista de Administração

Contemporânea, Edição Especial, Curitiba, v. 5, p. 183196, 2001.

\section{GARCIA, V. P. Desenvolvimento das famílias}

empresárias. Rio de Janeiro: Qualitymark, 2001.

\section{GUTIERREZ, G. L. Gestão comunicativa:}

maximizando criatividade e racionalidade. Rio de Janeiro: Qualitymark, 1999.

\section{HAMEL, G.; PRAHALAD, C. K. Competindo pelo}

futuro: estratégias inovadoras para obter o controle do seu setor e criar os mercados de amanhã. Rio de Janeiro: Campus, 1995.

HERZOG, L.T. Aproximación a la ventaja competitiva con base en los recursos. Boletín de Estudios

Económicos, Bilbao, v. LVI, n. 172, abril, 2001. 
INACIO, S. R. L. O comportamento do fundador $\boldsymbol{e}$ dos herdeiros da empresa familiar. 2006. Disponível em: <http://www.empresafamiliar.com.br/Artigos/Artigos. aspx>. Acesso em: $1^{\circ}$ jul. 2006.

\section{KAMOCHE, K. Strategic human resource} management within a resource-capability view of the firm. Journal of Management Studies, v. 33, n. 2, p. 213-234, march, 1996.

KING, A.W.; FOWLER, S.W.; ZETHAML, C.

Competências organizacionais e vantagem competitiva: o desafio da gerência intermediária. RAE, São Paulo, v. 42, n. 1, jan./mar. 2002 .

KROGH, G.; ROOS, J. A perspective on knowledge, competence and strategy. Personnel Review, v. 24, n. 3, p. 56-76, 1995.

LE BOTERF, G. De la compétence - Essai sur un attracteur étrange. Paris: Les Editions d'organisation, 1995.

Compétence et Navigation Professionnelle. Paris: Les Editions d'Organisation,1999.

\section{Desenvolvendo a competência dos}

profissionais. Porto Alegre: Artmed, 2003.

LEITE, J. B.D.; PORSEE, M. C. S. Competição baseada em competências e aprendizagem organizacional: em busca da vantagem competitiva. In: RUAS, R. L. et al.

Aprendizagem Organizacional e Competências. São Paulo: Bookman, 2005.

LEONE, N. M. C. P. G.; PEREIRA, S. L. Gestão de competência no gênero feminino. In: LEONE, N. M. C.

P. G. Empresa Familiar. Desvendando competências, racionalidades e afetos. São Paulo: Atlas, 2010.

McCLELLAND, D. C. Testing for Competence rather than Intelligence. American Psychologist, New York, v. 28, n. 1, p. 1-14, 1973.

McLAGAN, P. Competencies: the next generation. Training \& Development, ano 5, v. 51, mayo, 1997.

PAIVA, K.C.M.; MELO, M.C.O.L. Competências, gestão de competências e profissões: perspectivas de pesquisas. RAC - Revista de Administração Contemporânea, Curitiba, v. 12, n. 2, p. 339-368, abr./jun. 2008.
PERRENOUD, Philippe et al. As competências para ensinar no século XXI: formação dos professores e o desafio da avaliação. Porto Alegre: Artemed, 2001.

RABAGLIO, M. O. Seleção por competências. São Paulo: Educator, 2001.

Ferramentas de avaliação de performance com foco em competências. Rio de Janeiro:

Qualitymark, 2004.

RUAS, R. L. et al. Aprendizagem organizacional e competências. São Paulo: Bookman, 2005a.

O Conceito de Competência de A a Z - análise e revisão nas principais publicações nacionais entre 2000 e 2004. Anais... IX EnANPAD, 2005 b.

Gestão Por Competências: uma contribuição à perspectiva estratégica da gestão de pessoas. Anais... EnANPAD, 2003.

SANCHEZ, R. Managing knowledge into competence: the five learning cycles of the competent organization. In: SANCHEZ, R. Knowledgemanagement and organizational competence. Oxford: Oxford University Press, 2001. (Cap. 1, p. 3-37)

SILVA, N.N.; ARÁOZ, V. V. Mulheres do século XXI: uma série de possibilidades no desenvolvimento político, social e econômico. 2007. Disponível em: <www.revista. ulbrajp.edu.br/seer/inicia/ojs/include/getdoc.php?id=408\& article $=139 \&$ mode $=$ pdf $>$. Acesso em: $1^{\circ}$ jun. 2006.

SILVA, C. M.; HIPOLITO, J. M. H. Metodologia de Pesquisa Salarial por competências: aplicação e resultado. In. XXIV ENANPAD, Florianópolis, Anais... Santa Cataraina: Anpad, 2000.

SPENCER. L. M.; SPENCER, S. M. Competence at work: models for superior performance. England: John Wiley, 1993.

SVEIBY, K. E. A nova riqueza das organizações. Rio de Janeiro: Campus, 1998.

USSMAN, A. M. Empresas familiares: entender a estrutura, os valores e as dinâmicas da empresa familiar. Lisboa: Sílabo, 2004. 
Lydia Maria Pinto Brito • Nilda Maria de Clodoaldo Guerra Pinto Leone

VASCONCELOS, F. C.; CIRINO, Á. B. Vantagem

Competitiva: os modelos teóricos e a convergência entre estratégia e teoria organizacional. Revista de

Administração de Empresas, São Paulo, v. 40, n. 4, out./dez., 2000.

ZARIFIAN, P. Objectif compétence: pour une nouvelle logique. Paris: Editions Liaisons, 1999.

Objetivo competência. São Paulo: Atlas, 2001.

O modelo da competência: trajetória histórica,

desafios atuais e propostas. São Paulo: Senac São Paulo, 2003. 